\title{
Developing Student Skills to Actively Engage in Feedback Conversations: A Pilot Study
}

Neil Tuttle

Griffith University, n.tuttle@griffith.edu.au

Andrea Bialocerkowski

Griffith University, a.bialocerkowski@griffith.edu.au

Follow this and additional works at: https://nsuworks.nova.edu/ijahsp

Part of the Medical Education Commons, Physical Therapy Commons, and the Physiotherapy Commons

This Manuscript has supplementary content. View the full record on NSUWorks here: https://nsuworks.nova.edu/ijahsp/vol15/iss4/10

\section{Recommended Citation}

Tuttle N, Bialocerkowski A. Developing Student Skills to Actively Engage in Feedback Conversations: A Pilot Study. The Internet Journal of Allied Health Sciences and Practice. 2017 Jan 01;15(4), Article 10.

This Manuscript is brought to you for free and open access by the College of Health Care Sciences at NSUWorks. It has been accepted for inclusion in Internet Journal of Allied Health Sciences and Practice by an authorized editor of NSUWorks. For more information, please contact nsuworks@nova.edu. 


\title{
Developing Student Skills to Actively Engage in Feedback Conversations: A Pilot Study
}

\begin{abstract}
Purpose: Students often have passive or counterproductive responses to feedback. The aim of this pilot study was to evaluate a feedback training module containing online learning and live simulation. It was hypothesized that 1 ) student confidence in feedback skills would increase following the module, and 2) compared with a control group who undertook the module after their clinical placement, the feedback group who undertook the module before their placement would perform better on clinical placement on the sections of the Assessment of Physiotherapy Practice related to communication, but those related to clinical skills would not be affected. Methods: A convenience sample of all 68 students in the first of two years of a masters graduate-entry physiotherapy program in Australia was recruited for the study. The feedback group $(\mathrm{N}=46)$ received the module before their 5 -week orthopaedic clinical placement, and the control group $(\mathrm{N}=22)$ received the module after their placement. The module included two-hours of online independent learning and three-hours of simulated learning activity. Students provided and received feedback and were facilitated in developing skills to explore the understandings and attitudes underlying behaviours. Results: All students rated the module as having a large impact on their feedback abilities. The increased confidence in feedback skills was significant for the feedback group. Compared with the control group and with the previous two cohorts undertaking the same placement, the feedback group had improved performance at the mid-point, but not at the end of their five week placement. Conclusions: A focussed feedback module, including a simulated learning activity, increased student confidence and was perceived by students as having a positive impact on their feedback skills. There was a positive impact of the module on student performance during but not at the end of their clinic placement. An incidental finding was the suggestion that a time gap between on-campus learning and the related clinical placement may have a detrimental effect on student performance.
\end{abstract}

\section{Author Bio(s)}

Neil Tuttle, BSc, GradDipAdvManipTher, MPhil, PhD, is a Physiotherapist and Senior Lecturer in Physiotherapy in the School of Allied Health Sciences at Griffith University.on the Gold Coast in Australia

Andrea Bialocerkowski, BAppSc, MAppSc, GDipPubHlth,PhD, is a Physiotherapist and A/Prof and head of the School of Allied Health Sciences at Griffith University on the Gold Coast in Australia

\section{Acknowledgements}

The authors would like to acknowledge support for this project from the Australian Government. We would also like to thank NHETSIM for making their resources available and the students and facilitators who participated in the study. 


\title{
IJAHSP \\ The Internet Joumnal of Allied Health Sciences and Practice \\ Dedicated to allied health professional practice and education
}

Vol. 15 No. 4 ISSN 1540-580X

\section{Developing Student Skills to Actively Engage in Feedback Conversations: A Pilot Study}

\author{
Neil Tuttle, BSc, GradDipAdvManipTher, MPhil, PhD \\ Andrea Bialocerkowski, BAppSc, MAppSc, GDipPubHIth, PhD \\ Griffith University
}

Australia

\begin{abstract}
Purpose: Students often have passive or counterproductive responses to feedback. The aim of this pilot study was to evaluate a feedback training module containing online learning and live simulation. It was hypothesized that 1) student confidence in feedback skills would increase following the module, and 2) compared with a control group who undertook the module after their clinical placement, the feedback group who undertook the module before their placement would perform better on clinical placement on the sections of the Assessment of Physiotherapy Practice related to communication, but those related to clinical skills would not be affected. Methods: A convenience sample of all 68 students in the first of two years of a masters graduateentry physiotherapy program in Australia was recruited for the study. The feedback group $(\mathrm{N}=46)$ received the module before their 5-week orthopaedic clinical placement, and the control group ( $\mathrm{N}=22)$ received the module after their placement. The module included two-hours of online independent learning and three-hours of simulated learning activity. Students provided and received feedback and were facilitated in developing skills to explore the understandings and attitudes underlying behaviours. Results: All students rated the module as having a large impact on their feedback abilities. The increased confidence in feedback skills was significant for the feedback group. Compared with the control group and with the previous two cohorts undertaking the same placement, the feedback group had improved performance at the mid-point, but not at the end of their five-week placement. Conclusions: A focussed feedback module, including a simulated learning activity, increased student confidence and was perceived by students as having a positive impact on their feedback skills. There was a positive impact of the module on student performance during but not at the end of their clinic placement. An incidental finding was the suggestion that a time gap between on-campus learning and the related clinical placement may have a detrimental effect on student performance.
\end{abstract}

\section{INTRODUCTION}

Feedback is a critical element in learning clinical skills and has been defined as "a process whereby learners obtain information about their work in order to appreciate the similarities and differences between the appropriate standards for any given work and the qualities of the work itself in order to generate improved work." 1 Feedback is not, however, simply a one-way provision of information where information is "dangled" in front of the learner, but rather includes interactions, negotiation, and reflection with a goal of assisting the learner. ${ }^{2,3}$ Ideally, feedback is a curriculum-wide process where students seek, interpret, and apply feedback becoming "elicitors of knowledge."2 In the clinical education literature, it is suggested that feedback should focus on student behaviours. ${ }^{4}$ The processes of feedback described in the simulation literature, however, are intended to also promote critical reflection and deeper understanding of events. ${ }^{5}$ In other words, rather than only considering behaviours, the process explores the attitudes, understandings, and "frames" that underlie the learner's performance. ${ }^{6}$ The impact on performance resulting from the feedback is then more generalizable and has potential to influence other situations and tasks. In this paper, the term feedback includes the information and processes undertaken with an intention to improve not only specific behaviours related to clinical physiotherapy practice, but also aspects of the learner's understanding and underlying attitudes that have the potential to impact more broadly on their clinical performance.

In spite of the recognised importance of feedback and the extensive body of literature including theory and practice, feedback remains one of the most common areas where students express dissatisfaction. ${ }^{2}$ In the clinical setting, student dissatisfaction

(C) The Internet Journal of Allied Health Sciences and Practice, 2017 
may be more related to the quality rather than the quantity of feedback. ${ }^{7}$ One possible explanation for student dissatisfaction is that even with educators who indicated that feedback should be a two-way process, the student voice can make up less than $10 \%$ of the conversation. ${ }^{4}$

The majority of the feedback literature focuses on the development or evaluation of educator skills, but another approach to improving the feedback process is to improve student skills. Boud and Molloy describe eight curriculum features of a feedback model to improve performance and increase students' practice of self-regulation. ${ }^{1}$ They argue convincingly that students should understand approaches to feedback and should receive early instruction in feedback skills including their ability to seek feedback. There is limited literature evaluating the effectiveness of teaching feedback skills to healthcare students. Students who were provided with skills to seek feedback received an increased quantity of feedback. ${ }^{2}$ In medicine, "immunising" students by teaching them the concepts of feedback was not found to produce effective learning. ${ }^{8}$ When, however, practice of actually providing feedback was also included in the first year of a post-graduate medical course, the quality of feedback from students improved, and students reported increased confidence in providing and receiving feedback. ${ }^{9}$ The content delivered to students in these studies included strategies for students to provide effective feedback to their educators and to increase the quantity of feedback by actively seeking it from their educators.

A second aspect of how students can "upwardly manage" their clinical educators to get more out of the feedback process is for the students to take an active role in increasing the quality as well as the quantity of feedback they receive. Regardless of the frequency of feedback from their educators, students may not receive sufficient information to improve their performance. Unfortunately, when students do respond to feedback, their responses are often ineffective or even counterproductive. ${ }^{10}$ Students may only be aware of a limited number of options of how to respond to feedback. This limited repertoire was illustrated anecdotally by a student in one of our previous simulated learning activities, who when asked whether they might have other ways of responding to feedback, replied, "What do you expect; I can either take it on the chin or tell them what I think." Alternatively, students may simply need more information than what is being offered, or the feedback they receive may seem inconsistent with their prior learning or experience.

One way of potentially increasing student skills in expanding the feedback conversation is the advocacy inquiry (Al) approach. This approach is frequently taught as part of the process of providing feedback and is described more fully elsewhere. ${ }^{6}$ Rather than being strictly a method for providing feedback, the Al approach is perhaps best seen as a way of entering into a conversation about the "frames" (knowledge, understanding, and attitudes) that are behind an observed behaviour. Briefly, the approach starts from an underlying stance of curiosity and consists of three steps: 1) an objective observation, 2) a comparison with a possible alternative behaviour with an opinion as to why the alternative might have been better (or worse), and 3) an expression of genuine curiosity about the learner's perspective. The emphasis is therefore on frames behind the learner's behaviour rather than the specifics of the behaviour itself. Although the Al approach as described relates to providing feedback, it is also a useful tool in other areas of communication. For example, the authors have found the approach to be useful for students to gain more from feedback conversations by becoming better able to clarify or amplify information that is offered by their educators.

No previous studies were found that explicitly describe teaching feedback skills to health students in ways that include strategies to enhance the usefulness of the information that is offered by their educators. Neither does there appear to be any literature describing the effect of teaching feedback skills to allied health students generally or to entry-level physiotherapy students specifically. The aims of this pilot study were, following the development of a module to teach students feedback skills, to evaluate students' perceptions and whether there were any differences in performance on clinical placement by students who had participated in the feedback module before their clinical placement compared with those who did so after their clinical placement. If students' ability to learn from feedback improved, it was expected that their performance would also improve. Marks from clinical educators were considered to be an indication of student performance. It was hypothesised that 1) student confidence in providing and responding to feedback would improve, and 2) students who had undertaken the feedback module prior to their placement would perform better while on placement than those who received the feedback module after their placement, particularly in the areas of response to feedback and aspects of communication.

\section{METHODS}

A quasi-experimental pilot study was performed to investigate the effectiveness of a feedback module on student perceptions and performance. Ethical approval was obtained from the Griffith University Human Research Ethics Committee \# AHS/17/15/HREC. Neither author had any competing interests. One cohort of physiotherapy students ( $N=68)$ undertook a module in receiving and providing feedback which consisted of an online independent learning component and a live simulated clinical experience. The feedback group $(\mathrm{N}=46)$ received the module before their 5 -week orthopaedic clinical placement, and

(c) The Internet Journal of Allied Health Sciences and Practice, 2017 
the control group ( $\mathrm{N}=22)$ received the module after their placement. This pragmatic allocation was necessary because of the timing of clinical placements which could not be altered. Changes in student confidence in feedback skills, student perceived impact of the module on feedback skills, and student performance on clinical placement were used to evaluate the program.

\section{Participants and Setting}

The entire cohort of 68 students in the first year of a two-year graduate-entry Master of Physiotherapy program at Griffith University, Australia, consented to participate in the study. The allocation of groups was one of convenience based on when students were scheduled to attend their five-week full time orthopaedic inpatient clinical placement. The timing of each student's placement was not influenced by their previous on-campus performance, so no differences were expected between the groups. Both groups finished the on-campus content relevant to their orthopaedic placement at the same time. The schedules of students in each group are shown in Figure 1. In summary, the control group started their 5-week full time clinical placement the week after their on-campus orthopaedic inpatients block and did not undertake the feedback module until after their placement. The feedback group undertook the feedback module during a 5-week full time research course and then commenced their clinical placement either five or ten weeks after completing the on-campus orthopaedic inpatient content.

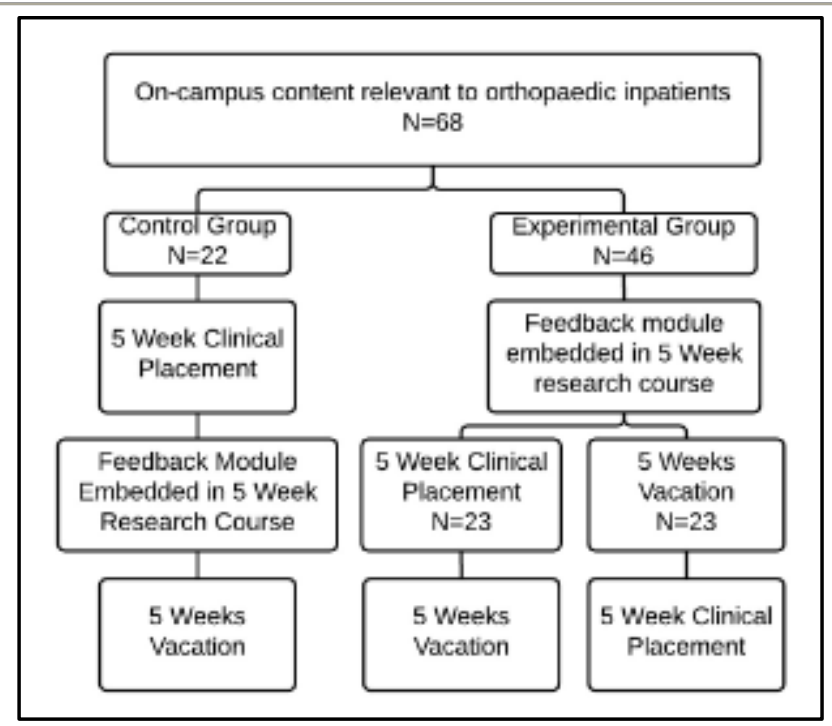

Previous work suggests standard deviations of 0.6 to 0.7 on similar five-point measures of confidence and impact to those used in the current study indicating that our sample size would have a power of 0.8 to detect differences greater than 0.5 points. ${ }^{11}$ The study, however, is underpowered to detect minimally meaningful changes in clinical placement performance. An effect size of 0.5 is considered necessary to be meaningful in student marks on clinical placement assessed by the APP, and according to the variance described, our study would have a power of 0.6 .12

\section{Instruments}

Levels one, two, and three of Kirkpatrick's four levels of evaluation were used for evaluation of the project. ${ }^{13}$ The questionaries used are included in Appendix 1. Kirkpatrick's first level, reaction, was evaluated by students' perceived impact following the module on their abilities to 1) respond verbally, 2) respond non-verbally, 3) be an active participant, and 4) improve their performance as a result of receiving feedback. Learning, the second level, was evaluated in relation to student confidence. Students were asked before and after the module to what extent they agreed, on a five point Likert scale from strongly disagree to strongly agree, that they were confident in their ability in relation to feedback in the same four areas of feedback skills. Behaviour is the third of Kirkpatrick's levels and was evaluated by performance of the students on clinical placement. Clinical educators consented to participate in this study and were informed that aspects of teaching were being evaluated, but were blinded to the specific aspects that were being evaluated and to the group allocation of the students. Student performance on clinical placements was evaluated with the Assessment of Physiotherapy Practice (APP) which is a validated and reliable clinical performance evaluation tool used by all entry-level physiotherapy programs in Australia as a summative assessment at the end of each placement and as a formative assessment mid-placement. ${ }^{12,14}$ The APP consists of 20 items, each scored on a scale of zero to four, with two indicating an acceptable, new graduate standard. These items are distributed across seven categories

(C) The Internet Journal of Allied Health Sciences and Practice, 2017 
(professional behaviour $(n=4)$; communication $(n=2)$; assessment $(n=3)$; analysis and planning $(n=4)$; intervention $(n=5)$; evidence based practice $(n=1)$, risk management $(n=1))$.

The findings on primary analysis suggested that there may have been an effect of how long after their on-campus content the students had undertaken their placement. Since the curriculum from the previous two cohorts was not different from the cohort included in this study in any known ways except for the inclusion of the feedback module, the APP scores from these years were also compared with the findings in the current study. The intention of including this historical data was firstly, that it increased the sample size of the control group, but also that it could provide an indication of whether differences found in the primary analysis may have been related to how long students' clinical placements occurred after their on-campus content rather than to the feedback module.

\section{Procedures}

The learning objectives for the module were 1) to understand various models for providing feedback; 2) to experience how emotional responses can impact on the effectiveness of feedback conversations; 3 ) to be able provide and respond to feedback to ensure that the learner understands how their performance compares with expectations, has strategies to improve their performance in the future, and is facilitated to reflect on the knowledge, attitudes, and values that underlie their performance; and 4) to be able to use an advocacy enquiry approach as part of the conversation when both providing and responding to feedback.

The module consisted of two components: 1) an online feedback and debriefing independent learning module from the NHETSim Program, an Australian initiative for educating simulation educators taking approximately two hours to complete and 2) a threehour simulated learning activity which included taking a history of a simulated patient (SP) as a starting point for practicing providing and receiving feedback. ${ }^{15}$ The SP had a condition comparable to the orthopaedic conditions that the students would be expected to treat in their upcoming clinical placement. The online module included several theories on feedback including the Al approach. Importantly, the module was designed for simulation educators and the content was therefore targeted to providing rather than receiving of feedback. Several methods of feedback were covered in the online module, including the Al approach.., 16

The simulated learning activity started from an assumption that learners are intelligent, well trained, care about doing their best, and want to improve. ${ }^{17}$ According to the readiness to change model, the learners are presumed to be beyond the precontemplation stage so would be expected to be aware of having gaps in their knowledge or skills. ${ }^{18}$ The activity commenced with a pre-briefing, including 1) the structure of the session; 2) that students providing feedback should use methods from the online module to extend the content beyond behaviours to include the "frames" (knowledge, understanding and attitudes) that underlie the behaviours; and 3 ) that the feedback from the SP would be part of the simulation rather than an accurate indication of performance. Groups of four students (A, B, C, and D) worked with one facilitator and one SP for 90 minutes and with a different facilitator and SP for an additional 90 minutes.

Initially, student A took a history of the SP for five to ten minutes, followed by student B providing feedback to student $A$, and the facilitator providing feedback in the style of a simulation debriefing discussion. ${ }^{16}$ The SP provided feedback to student $A$ on communication aspects of their interaction. The SP had been instructed to provide exaggerated positive feedback on the student's interaction which when contrasted with their peer's feedback, provided the opportunity for discussion and reflection on student A's responses when positive or inconsistent feedback was provided or when the feedback was not consistent with their perception. The SP then provided a second, accurate version of their feedback. The focus moved to providing feedback to student $B$ who provided the initial feedback to student $A$, and a similar pattern was repeated until every student had been in each role. The feedback from the SP was always exaggerated, but with their interactions with students $B, C$ or $D$, it could be either in a positive or negative direction. Through the course of the session, each student therefore 1) took a patient history, 2) provided primary feedback to one of their peers who had taken the history, and 3) received and responded to feedback from several sources - their peer providing primary feedback, the SP providing exaggerated and accurate feedback, and the facilitator. Students providing and receiving feedback were encouraged to include an expression of curiosity as used in the Al approach to enable them to augment or amplify the information the learner was receiving or that they were being offered by way of feedback. Repeated deliberate practice where students repeated part of one of the feedback conversations was used to ensure students succeeded in achieving the intended outcomes.

(C) The Internet Journal of Allied Health Sciences and Practice, 2017 


\section{Analyses}

Descriptive statistics were calculated for all dependent variables. Means and $95 \%$ confidence intervals (Cl) were calculated for change in confidence and perceived impact variables following the feedback module. Ninety-five percent confidence intervals were calculated using bootstrapping with 1000 resamples and differences were considered significant when the Cls did not overlap. Although the assumptions of parametric statistics could be seen to be violated by the Likert scale data being ordinal and the size of some group sizes, an ANOVA was considered to be an appropriate method of statistical analysis for the data in the current study. ${ }^{19}$ One-way ANOVAs were used to determine if there were differences in student performance on the end-ofplacement and mid-placement APPs between the control and feedback groups.

The findings on the primary analysis suggested that there may have been an effect of how long after their on-campus content the students had undertaken their placement. Because the curriculum from the previous two cohorts was not different from the cohort included in this study in any known ways except for the inclusion of the feedback module, the APP scores from the corresponding placement in these years were also compared with the findings in the current study. The intention of including this historical data was firstly that it increased the sample size of the control group, but also that it could provide an indication of whether differences indicated from the primary analysis may have been related to how long students' clinical placements occurred after their on-campus content rather than to the feedback module. Post hoc analyses were undertaken to determine if differences found between the experimental and control groups in the mid-placement APPs could be related to the timing of the clinical placement. A one-way ANOVA was conducted between the groups in the current study, and mid-placement APP data of the two previous cohorts with cohort, timing of placement (placement immediately following relevant on-campus contend or delayed), and having received feedback as factors.

\section{RESULTS}

\section{Student Perceptions}

Fifty-three of the 68 students completed the pre- and post-module questionnaires. Figure 2 shows student confidence increased significantly for the feedback group in all four areas (respond verbally to feedback, respond non-verbally to feedback, be an active participant in feedback, and ability to change in response to feedback). The control group $(n=22)$, who participated in the feedback module after their placement, had higher pre-module confidence in all areas, and only the increase in their ability to respond verbally post module reached statistical significance. There were no significant differences between groups in their confidence after the feedback module even though the feedback group had not yet undertaken their clinical placement at this time.

Student perceived impact of the module is shown in Figure 3. Both groups of students reported that the module made them better prepared for providing and receiving feedback. There were, however, no differences in impact ratings between the feedback and control groups.

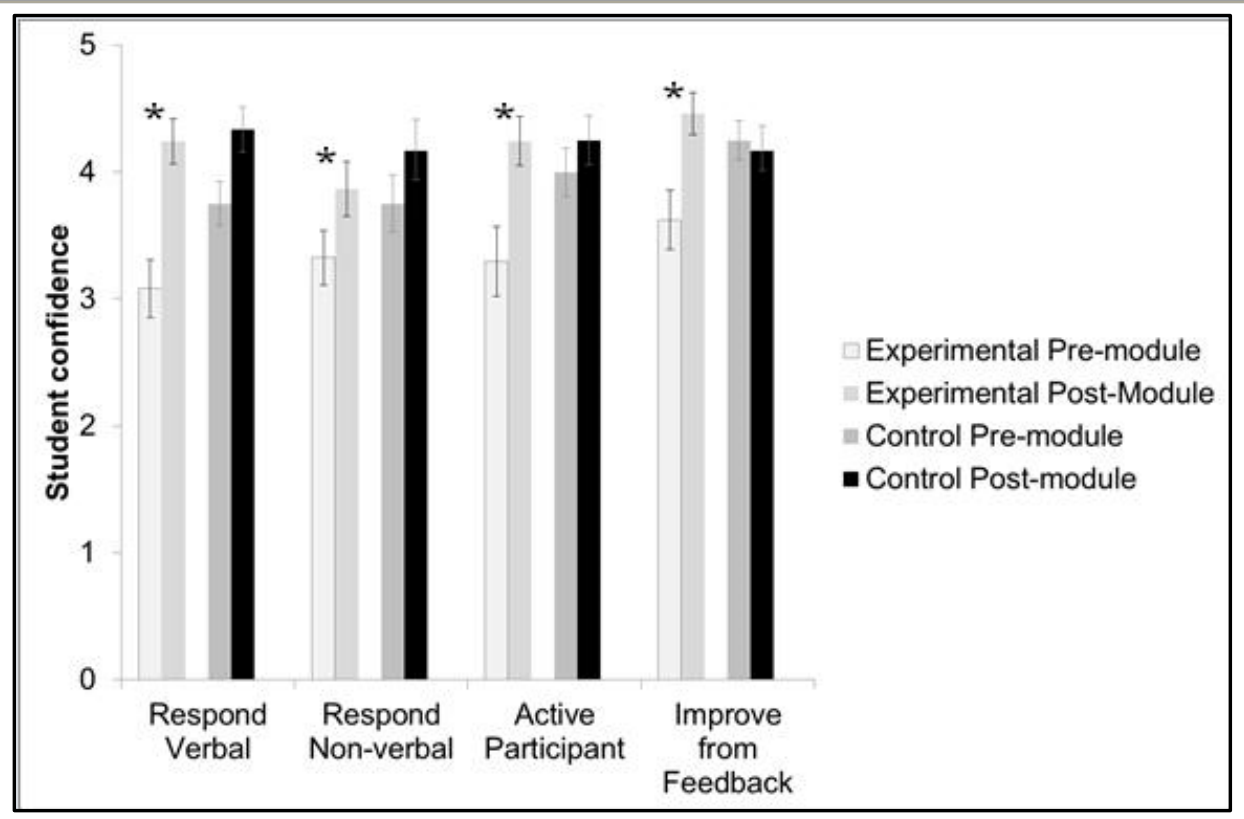

(c) The Internet Journal of Allied Health Sciences and Practice, 2017 


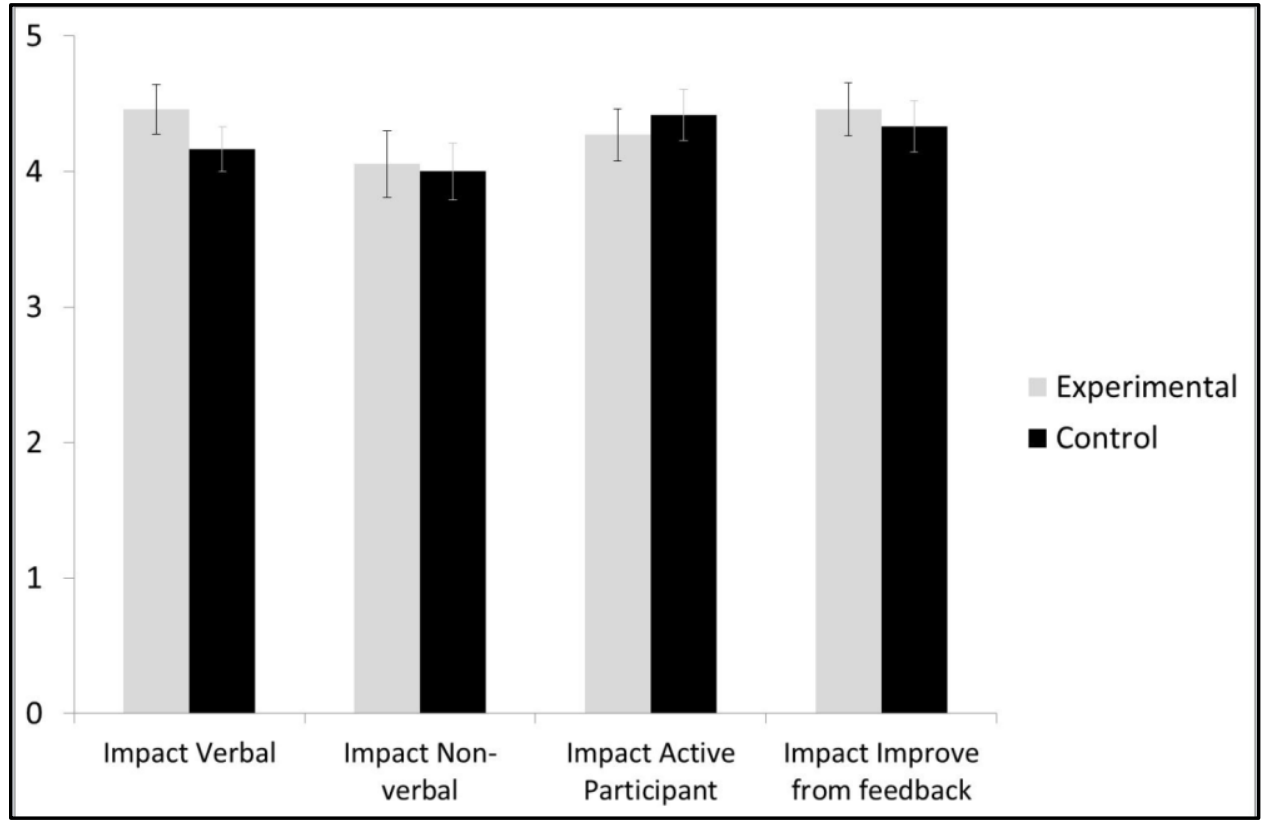

\section{Student Performance}

There was a $100 \%$ response rate for the end-of-placement APP, as its completion by clinical educators is mandatory. There was no significant difference between the control and experimental group in the total scores, (3.15/4, SD \pm 0.58 and $3.09 / 4, S D$ \pm 0.5 respectively, $p=0.62$ ) or for the any of the individual items $(p=0.10$ to 0.98$)$. For the mid-placement APP, there were 26 responses from clinical educators ( 14 feedback, 11 control). Students in the feedback group scored significantly higher on item 3 (demonstrates ethical, legal, and culturally sensitive practice, $p=0.04$ ) and item 20 (identifies adverse events/near misses and minimises risk associated with assessment and interventions, $p=0.02$ ).

\section{Comparison of Mid-placement APPs with Previous Cohorts}

Considering the small response rate for the mid-placement APP and the recognition that the time between students finishing their on-campus content and their clinical placement could impact on student performance, post hoc analysis was conducted to compare APPs for the current cohort with the previous two years. The feedback group performed better than the comparable group of the historical data on items $11,13,19$, and 20 ( $p=0.003,0.032,0.002$, and 0.006 respectively). The control group performed better than historical data on items 9 , and 19 , but worse on item 3 ( $p=0.039,0.05$, and 0.015 respectively). There were two items (items 8 and 9 ) where the current group as a whole performed better than the historical data $(p=0.034$ and $<0.001$ respectively). Interestingly, while the feedback group performed better on several items than their peers, the analogous delayed placement group in the historical data performed worse on a larger number of items (specifically $3,4,8,11$, and 20) than students in the same years who went directly onto placement $(p=0.010,0.032,0.001$, and 0.021 respectively). 
Table 1. Mid-placement APP scores

\begin{tabular}{|c|c|c|c|c|c|c|}
\hline \multirow[t]{2}{*}{ Mid-Placement } & \multicolumn{3}{|c|}{2015} & \multicolumn{3}{|c|}{$2013 / 2014$} \\
\hline & $\begin{array}{c}\text { Control } \\
(\mathrm{n}=11) \\
\text { (Immediate } \\
\text { Placement) }\end{array}$ & $\begin{array}{l}\text { Feedback } \\
(n=14) \\
\text { Delayed } \\
\text { Placement }\end{array}$ & $\begin{array}{c}\text { Total } \\
(\mathrm{n}=25)\end{array}$ & $\begin{array}{l}\text { Immediate } \\
\text { Placement } \\
(n=48)\end{array}$ & $\begin{array}{c}\text { Delayed } \\
\text { Placement } \\
(\mathrm{n}=71)\end{array}$ & $\begin{array}{c}\text { Total } \\
(\mathrm{n}=119)\end{array}$ \\
\hline \multicolumn{7}{|l|}{ Professional Behaviour } \\
\hline $\begin{array}{l}\text { 1. Patient/client rights } \\
\text { and consent }\end{array}$ & $2.7(0.47)$ & $2.8(0.43)$ & $2.7(0.44)$ & $2.9(0.78)$ & $2.6(0.69)$ & $2.7(0.68)$ \\
\hline $\begin{array}{l}\text { 2. Demonstrates } \\
\text { Commitment to learning }\end{array}$ & $2.5(0.82)$ & $2.4(0.65)$ & $2.5(0.71)$ & $2.6(0.89)$ & $2.5(0.80)$ & $2.5(0.80)$ \\
\hline $\begin{array}{l}\text { 3. Ethical, legal, }{ }^{* *} \\
\text { culturally sensitive } \\
\text { practice }\end{array}$ & $2.5(0.52)^{\star} \ddagger$ & $2.9(0.36)^{*}$ & $2.7(0.46)$ & $3.0(0.61)^{\star *} \ddagger$ & $2.7(0.62)^{\star *}$ & $2.8(0.62)$ \\
\hline 4. Teamwork & $2.4(0.50)$ & $2.5(0.85)$ & $2.4(0.71)$ & $2.4(0.82)^{* \star}$ & $2.1(0.68)^{* *}$ & $2.3(0.76)$ \\
\hline \multicolumn{7}{|l|}{ Communication } \\
\hline 5. Communication & $2.4(0.67)$ & $2.3(0.47)$ & $2.3(0.56)$ & $2.3(0.69)$ & $2.2(0.62)$ & $2.3(0.65)$ \\
\hline 6. Documentation & $2.5(0.52)$ & $2.4(0.75)$ & $2.4(0.65)$ & $2.1(0.70)$ & $2.2(0.71)$ & $2.1(0.70)$ \\
\hline \multicolumn{7}{|l|}{ Assessment } \\
\hline $\begin{array}{l}\text { 7. Appropriate } \\
\text { patient/client interview }\end{array}$ & $2.5(0.52) \ddagger$ & $2.4(0.50)$ & $2.4(0.51)$ & $2.2(0.59) \ddagger$ & $2.3(0.58)$ & $2.2(0.59)$ \\
\hline $\begin{array}{l}\text { 8. Selects and measures } \\
\text { relevant indicators and } \\
\text { outcomes \# }\end{array}$ & $2.3(0.65)$ & $2.4(0.50)$ & 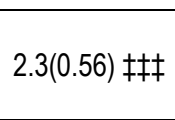 & $2.2(0.74)^{\star \star}$ & $1.8(0.59)^{* *}$ & 2.0(0.67) 㧊 \\
\hline $\begin{array}{l}\text { 9. Performs appropriate } \\
\text { physical assessment } \\
\text { procedures }\end{array}$ & $2.6(0.50) \ddagger$ & $2.4(0.63)$ & $2.5(0.56) \ddagger \ddagger \ddagger$ & $2.2(0.58) \ddagger$ & $1.9(0.57)$ & $2.0(0.59) \neq \ddagger \ddagger$ \\
\hline \multicolumn{7}{|l|}{ Analysis ${ }^{* *}$ Planning } \\
\hline $\begin{array}{l}\text { 10. Appropriately } \\
\text { interprets assessment } \\
\text { findings }\end{array}$ & $2.3(0.47)$ & $2.4(0.51)$ & $2.4(0.49)$ & $2.2(0.74)$ & $2.0(0.72)$ & $2.1(0.72)$ \\
\hline $\begin{array}{l}\text { 11. Identifies and } \\
\text { prioritises } \\
\text { patient's/client's problems }\end{array}$ & $2.3(0.47)$ & $2.3(0.47)$ 拉 & $2.3(0.46)$ & $2.2(0.75)^{\star \star}$ & $1.8(0.58)^{* *} \neq \ddagger$ & $2.0(0.68)$ \\
\hline $\begin{array}{l}\text { 12. Sets realistic short } \\
\text { and long term goals }\end{array}$ & $2.2(0.60)$ & $1.9(0.47)$ & $2.0(0.54)$ & $1.9(0.84)$ & $1.7(0.68)$ & $1.8(0.76)$ \\
\hline $\begin{array}{l}\text { 13. Selects appropriate } \\
\text { intervention }\end{array}$ & $2.2(0.40)$ & $2.4(0.51)$ 㧊 & $2.3(0.48)$ & $2.1(0.71)$ & $2.0(0.64) \neq \ddagger$ & $2.0(0.67)$ \\
\hline \multicolumn{7}{|l|}{ Intervention } \\
\hline $\begin{array}{l}\text { 14. Performs } \\
\text { interventions } \\
\text { appropriately }\end{array}$ & $2.4(0.50)$ & $2.3(0.61)$ & $2.3(0.56)$ & $2.2(0.59)$ & $2.0(0.67)$ & $2.1(0.64)$ \\
\hline $\begin{array}{l}\text { 15. Is an effective } \\
\text { educator \# }\end{array}$ & $2.4(0.67)$ & $2.2(0.43)$ & $2.3(0.54)$ & $2.1(0.73)$ & $1.9(0.66)$ & $2.0(0.69)$ \\
\hline $\begin{array}{l}\text { 16. Monitors the effect of } \\
\text { intervention }\end{array}$ & $2.3(0.47)$ & $2.4(0.65)$ & $2.4(0.57)$ & $2.3(0.69)$ & $2.0(0.70)$ & $2.1(0.71)$ \\
\hline $\begin{array}{l}\text { 17. Progresses } \\
\text { intervention appropriately }\end{array}$ & $2.1(0.54)$ & $2.1(0.62)$ & $2.1(0.57)$ & $2.0(0.75)$ & $2.0(0.60)$ & $2.0(0.67)$ \\
\hline $\begin{array}{l}\text { 18. Undertakes discharge } \\
\text { planning }\end{array}$ & $2.1(0.54)$ & $1.9(0.47)$ & $2.0(0.50)$ & $2.0(0.79)$ & $1.8(0.53)$ & $1.8(0.62)$ \\
\hline \multicolumn{7}{|l|}{$\begin{array}{l}\text { Evidence-based } \\
\text { Practice }\end{array}$} \\
\hline $\begin{array}{l}\text { 19. Applies evidence } \\
\text { based practice in patient } \\
\text { care \# }\end{array}$ & $2.5(0.82) \ddagger$ & 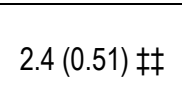 & $2.4(0.65)$ & $2.0(0.75) \ddagger$ & $1.9(0.55)$ 拉 & $2.0(0.64)^{\star *}$ \\
\hline \multicolumn{7}{|l|}{ Risk Management } \\
\hline $\begin{array}{l}\text { 20. Identifies adverse } \\
\text { events/near misses and } \\
\text { minimises risk }\end{array}$ & $2.2(0.40)^{*}$ & $2.6(0.51)^{\star} \ddagger \ddagger$ & $2.4(0.50)$ & $2.4(0.76)^{* *}$ & $2.1(0.63)^{\star *} \neq \ddagger$ & $2.3(0.67)$ \\
\hline
\end{tabular}


Significant differences are indicated by *control and feedback groups (Immediate and Delayed placements) 2015; ** Immediate

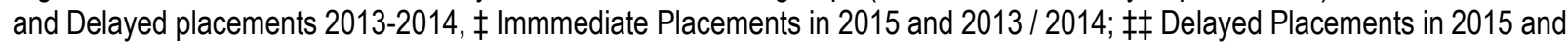

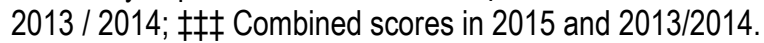

\section{DISCUSSION}

The results of this pilot study indicate that student confidence in providing and receiving feedback increased following a feedback module including conceptual and practical content. Students rated the impact of the module highly, although this was more apparent for the students who had not yet been on their clinical placement. There were no differences in end-of-placement student performance as rated by clinical educators using the APP, but students who received the feedback module before their placement performed better on item 3 (demonstrates ethical, legal and culturally sensitive practice); and item 20 (identifies adverse events/near misses and minimises risk associated with assessment and interventions) of the mid-placement APP.

\section{Student Confidence}

The feedback group had a significant increase in confidence in each of the four areas that were evaluated (respond verbally to feedback, respond non-verbally to feedback, be an active participant in feedback, and ability to change in response to feedback). As might be expected due to their exposure to live feedback conversations, the confidence of the control group prior to completing the module was higher than the experimental group. There was a trend to increased confidence in all areas by the control group, but this increase was only significant for responding verbally to feedback. No differences in post module confidence were detected between the feedback and control groups. The confidence of the feedback group was not retested after they had completed their clinical placement, so it cannot be determined whether their confidence had increased further.

Students rated the impact of the feedback module similarly high regardless of whether they participated before or after their clinical placement. A high rating of the impact of the module without a significant improvement in confidence for the postplacement group raises some interesting questions. One of the difficulties with self-reporting of confidence is that the student needs to compare what they know with what they think there is to know. In their systematic review, Davis et al found the relationship between self-assessment of confidence and objective measures of competence in medical education was often inverse. ${ }^{20}$ In other words, a higher confidence corresponded with poorer performance. There was some evidence, however, that the concordance between confidence and competence increased with further training and experience. In an unpublished evaluation of one of our other simulated learning projects, students rated their confidence as lower after the simulation, but rated the impact of the learning as high. Our impression was that although their competence improved, the students also recognised that there was more to know than they had previously imagined - they knew more of what they did not know. Our tendency, therefore, is to value self-assessment of impact more highly than changes in confidence.

\section{Evaluation by Clinical Educators}

There were no significant differences in scores by the clinical educators on the final APP between the feedback and control groups. This result is consistent with the findings of the only other study we are aware of in physiotherapy which investigated the impact of simulation on student performance on clinical placement where no change in APP scores were found following a cardiorespiratory simulation module. ${ }^{21}$

Initially, the authors simplistically expected any changes that occurred as a result of the feedback module would be most likely to be in relation to communication and specifically responses to feedback. On reflection, however, it would seem that a more efficient feedback process could, and perhaps should, result in greater improvement or greater rate of improvement in any or all aspects of student performance. While the final APP scores represent the competence of students at the end of placement, the mid-placement APP scores could be indicative of either the rate of progress during the first half of the placement, or student competence when starting the placement. The feedback group performed better than the control group on items 3 and 20 in the mid-placement APP (ethical, legal and culturally sensitive practice, and identifying and minimising risks), but not in item 2 (demonstrated commitment to learning) where response to feedback is specifically mentioned in the descriptors. Item 20 (identifying and minimising risk) is arguably one of the most critical elements of student performance, and this item that showed effect sizes of over seven for superiority of the feedback group over both the control group and the corresponding historical data.

In contrast with the superiority of the feedback over the control group, the mid-placement APPs from the historical data showed the delayed placement group performed worse on five out of the twenty items. Although there are a number of factors that could influence this finding, there is a suggestion that a delay between on-campus content and clinical placement may adversely impact on student competence at the beginning of clinical placements. If this is the case, the impact of the feedback module in the current study may have been underestimated. There are also implications for curriculum design if student performance, even

() The Internet Journal of Allied Health Sciences and Practice, 2017 
in the first half of a clinical placement, is affected by a delay between on-campus learning and related clinical placements. The sooner students can reach a degree of independence, the more value they are to the facilities where they undertake their clinical placements, so students being more competent at the beginning of placements could make them more desirable for the clinical placement facilities.

The lack of difference in the final APP scores therefore could be due to the students in the feedback group improving more quickly, but the control group "catching up" by the end of the placement. Alternatively, if students in the feedback group who had a delay before starting their placement had a lower starting point as is suggested from the historical data, any positive affect of the feedback module may have been offset by a poorer starting point. The results of this study are far from conclusive, but the authors considered them promising enough to have instituted a feedback module as part of the curriculum for all students. As always, the findings of this study raise more questions than they answer. Mixed methods studies may assist in clarifying the effect of feedback training on both student and educator experiences. The incidental finding of a suggestion of delay in clinical placement adversely affecting student performance is the subject of further investigation.

\section{Innovative Features}

There is a limited amount of literature on educating students in how to give and receive feedback or in how to best utilise feedback to increase their clinical performance. No studies were found that specifically addressed training students to increase the quality of information they receive. The use of feedback skills generally and the Al approach specifically are well suited to enabling students to augment or amplify the information they receive from educators without evoking the type of defensive response that can occur when educators feel they are being challenged. ${ }^{22}$

\section{Limitations}

An apparent limitation in the study design is that the sample size was relatively small. Although all students in the cohort agreed to participate, not all students completed the questionnaires. Had they all responded, there would have been sufficient power to detect the expected magnitude of changes in student confidence. The questions used for confidence and impact were not specifically evaluated for validity or repeatability. For performance on clinical placements, the power was not sufficient to effectively detect an effect size of 0.5 , which was considered a minimally meaningful difference in performance, so differences may exist besides those that were found in the current study. Nonetheless, the current sample size was sufficient to detect the observed effect sizes of over seven for some items.

It cannot be concluded that the differences that were found are related to the feedback module. There was one important difference between the feedback and control groups besides the presence of the feedback module. The control group had their clinical placement immediately after their relevant on-campus content. The feedback group had a gap of five to ten weeks before their clinical placement which may have impacted on their performance during the clinical placement. Comparison with historical data, however, suggested that the improvements found in the feedback group were not consistent with differences between similarly timed placements in previous cohorts. The authors could not be certain that the starting points of the groups in this study were comparable. The variations that appear between groups who had their clinical placements at different times in the historical data suggest that some differences between groups in this study are also quite possible. Allocation to the feedback and control groups was not randomized, but assignment to groups was not influenced by past or expected performance. The APP used to evaluate student performance may have been unresponsive to change, and there may have been a ceiling effect for some measures. Using the current study design, it was not possible to calculate relationships between student and educator responses because student responses were anonymous. Feedback training has been combined with other curriculum content for subsequent years, so this study was able to take advantage of a one-off opportunity to investigate the effects of a feedback module on student performance. Although the results of this study appear to support the inclusion of feedback training, the findings of this study need to be interpreted with caution. It was not possible to determine the similarity of groups or of cohorts when compared with historical data.

\section{CONCLUSIONS}

Students considered the feedback module to increase their confidence and have a strong positive impact on their feedback skills. Although there were no differences in student performance as rated by clinical educators at the end of the placements, several differences were found for the mid-placement APP scores including possible reversal of a negative trend that would be suggested by historical data.

() The Internet Journal of Allied Health Sciences and Practice, 2017 


\section{REFERENCES:}

1. Boud D, Molloy E. Feedback in Higher and Professional Education: Understanding it and doing it well. Routledge; 2013.

2. Boud D, Molloy E. Rethinking models of feedback for learning: the challenge of design. Assessment \& Evaluation in Higher Education. 2013;38(6):698-712.

3. Connor DM, Chou CL, Davis DL. Feedback and Remediation: Reinforcing Strengths and Improving Weaknesses. In: Kalet A, Chou CL, eds. Remediation in Medical Education: A Mid-Course Correction. New York, NY: Springer New York; 2014. p. 249-63.

4. Molloy E. Time to pause: giving and receiving feedback in clinical education. In: Boyd BS, Molloy E, editors. Feedback in higher and professional education: understanding it and doing it well. Routledge; 2013. p. 128-45.

5. Eppich W, Cheng A. Promoting Excellence and Reflective Learning in Simulation (PEARLS): Development and Rationale for a Blended Approach to Health Care Simulation Debriefing. Simul Healthc. 2015;10(2):106-15. doi: 10.1097/SIH.0000000000000072. [PMID: 25710312]

6. Rudolph JW, Simon R, Rivard P, Dufresne RL, Raemer DB. Debriefing with good judgment: combining rigorous feedback with genuine inquiry. Anesthesiol Clin. 2007;25(2):361-76. doi: 10.1016/j.anclin.2007.03.007. [PMID: 17574196]

7. Strong J, Hughes C, Wilson W, Arnott W, Isles R, Bennison A. Perceptions of feedback among undergraduate and postgraduate students of four health science disciplines. Internet Journal of Allied Health Sciences and Practice. 2012;10(4):1-7.

8. Henderson P, Ferguson-Smith AC, Johnson MH. Developing essential professional skills: a framework for teaching and learning about feedback. BMC <edical Education. 2005;5(1):11.

9. Kruidering-Hall M, O'Sullivan PS, Chou CL. Teaching feedback to first-year medical students: Long-term skill retention and accuracy of student self-assessment. J Gen Intern Med. 2009;24(6):721-6. [PMID: 19384559]

10. Clynes MP, Raftery SE. Feedback: an essential element of student learning in clinical practice. Nurse Educ Pract. 2008;8(6):405-11. [PMID: 18372216]

11. Faul F, Erdfelder E, Lang AG, Buchner A. G*Power 3: a flexible statistical power analysis program for the social, behavioral, and biomedical sciences. Behav Res Methods. 2007;39(2):175-91. Epub 2007/08/19. [PMID: 17695343]

12. Dalton M, Davidson M, Keating JL. The assessment of physiotherapy practice (APP) is a reliable measure of professional competence of physiotherapy students: a reliability study. J Physiother. 2012;58(1):49-56. [PMID: 22341382]

13. Eseryel D. Approaches to evaluation of training: theory \& practice. Educational Technology \& Society. 2002;5(2):93-8.

14. Dalton M, Davidson M, Keating J. The Assessment of Physiotherapy Practice (APP) is a valid measure of professional competence of physiotherapy students: a cross-sectional study with Rasch analysis. J Physiother. 2011;57(4):239-46.

15. The NHET-SimMonashTeam. The National Health Education and Training - Simulation Program 2012 [updated December 16, 2015]. Available from: http://www.nhet-sim.edu.au.

16. Rudolph JW, Simon R, Dufresne RL, Raemer DB. There's no such thing as "nonjudgmental" debriefing: a theory and method for debriefing with good judgment. Simul Healthc. 2006;1(1):49-55. [PMID: 19088574]

17. Rudolph JW, Simon R, Raemer DB, Eppich WJ. Debriefing as formative assessment: closing performance gaps in medical education. Acad Emerg Med. 2008;15(11):1010-6. doi: 10.1111/j.1553-2712.2008.00248.x. [PMID: 18945231]

18. Prochaska JO, DiClemente CC. Transtheoretical therapy: Toward a more integrative model of change. Psychotherapy: Theory, Research \& Practice. 1982;19(3):276.

19. Norman G. Likert scales, levels of measurement and the "laws" of statistics. Adv Health Sci Educ Theory Pract. 2010;15(5):625-32. [PMID: 20146096]

20. Davis DA, Mazmanian PE, Fordis M, Van Harrison R, Thorpe KE, Perrier L. Accuracy of physician self-assessment compared with observed measures of competence: a systematic review. JAMA. 2006;296(9):1094-102. [PMID: 16954489]

21. Jones A, Sheppard L. Use of a human patient simulator to improve physiotherapy cardiorespiratory clinical skills in undergraduate physiotherapy students: a randomised controlled trial. Internet Journal of Allied Health Sciences and Practice. 2011;9:1-11.

22. Reddy ST, Zegarek MH, Fromme HB, Ryan MS, Schumann S-A, Harris IB. Barriers and facilitators to effective feedback: a qualitative analysis of data from multispecialty resident focus groups. J Grad Med Educ. 2015;7(2):214-9. [PMID: 26221437] 